\title{
CORREÇÃO DA ACIDEZ DO SOLO, CRESCIMENTO RADICULAR E NUTRIÇÃO DO MILHO DE ACORDO COM A CALAGEM NA SUPERFÍCIE EM SISTEMA PLANTIO DIRETO(1)
}

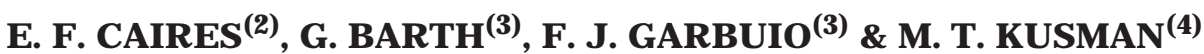

\begin{abstract}
RESUMO
Os efeitos das alterações químicas do solo, decorrentes da calagem na superfície, em sistema plantio direto, no crescimento radicular e na nutrição do mil ho não são muito conhecidos. Com o objetivo de estudar a correção da acidez do solo, o crescimento de raízes de milho (híbrido AG 9090), a nutrição da planta e seus reflexos sobre a produção de grãos, considerando a aplicação superficial de calcário no sistema plantio direto, foi realizado um experimento em um Latossolo Vermelho distrófico textura média, em Ponta Grossa (PR). 0 delineamento experimental empregado foi o de blocos ao acaso em parcelas subdivididas, com três repetições. As parcelas receberam quatro doses de calcário dolomítico na superfície (0, 2, 4 e 6 t ha-1), em julho de 1993, e, nas subparcelas, foram reaplicadas duas doses de calcário dolomítico na superfície ( 0 e $3 \mathrm{t} \mathrm{ha}^{-1}$ ), em junho de 2000. A calagem, após 92 meses, aumentou o pH, o Ca trocável ea saturação por bases e reduziu o Al trocável do solo, até à profundidade de $0,60 \mathrm{~m}$. A reaplicação de calcário, após nove meses, proporcionou aumento no pH, Ca trocável e saturação por bases e redução no Al trocável do solo, até à profundidade de $0,20 \mathrm{~m}$. A reação do calcário reaplicado na superfície foi mais rápida em condições de maior acidez do solo. Não houve limitação do crescimento radicular e da produção de milho para concentração de $10 \mathrm{mmol}_{\mathrm{c}} \mathrm{dm}^{-3} \mathrm{de}$ Al trocável, na ausência de déficit hídrico em solo com alto teor de matéria orgânica, mas a calagem na superfície melhorou a distribuiç̧ão relativa de raízes na presença de solo compactado. O calcário dolomítico aplicado na superfície em plantio direto proporcionou redução no teor de K no tecido foliar do milho, sem alterar a produção de grãos.
\end{abstract}

Termos de indexação: Zea mays L., calcário dolomítico, cálcio, alumínio, nutrição mineral, sistema radicular.

(1) Trabal ho realizado com apoi o financeiro do CNPq. Recebido para publicação em outubro de 2001 e aprovado em julho de 2002.

(2) Professor do Departamento de Ciência do Solo e Engenharia Agrícola, Universidade Estadual de Ponta Grossa - UE PG. Av. Gal . Carlos Cavalcanti, 4748, CE P 84030-900 Ponta Grossa (PR). Bolsista do CNPq. E-mail: efcaires@uepg.br

(3) Aluno do curso de Agronomia, PIC/UEPG.

(4) Aluno do curso de Agronomia, Bolsista do PIBIC/CNPq. 


\title{
SUMMARY: INFLUENCE OF SURFACE LIME APPLICATION IN A NO- TILLAGE SYSTEM ON SOIL ACIDITY, CORN ROOT GROWTH AND NUTRITION
}

\begin{abstract}
The effects of superficial limeapplication on chemical soil characteristics in no-tillage systems and its influence on root growth and mineral nutrition in maizecrops has not been thoroughly investigated yet. To eval uate these effects on maize (hybrid AG 9090) and its reflexes on the grain yield performance under no-tillage, a field trial was carried out on a dystrophic Red Latosol (Hapludox) in Ponta Grossa, State of Paraná, Brazil. A compl etely randomized block design with threereplications was used in a split-plot experiment. In the main plots, four rates of dol omitic limestone were applied on the surface $\left(0,2,4\right.$ and $\left.6 \mathrm{t} \mathrm{ha}^{-1}\right)$ in J uly 1993, and two rates of dolomitic limestone $\left(0\right.$ and $\left.3 \mathrm{t} \mathrm{ha}^{-1}\right)$ reapplied on the surface of thesubplots in J uneof 2000. After 92 months, liming had decreased theexchangeableAl and increased $\mathrm{pH}$, exchangeable $\mathrm{Ca}$ and soil base saturation values, down to a depth of $0.60 \mathrm{~m}$. Si milar effects were observed ni nemonths after limereapplication down a depth of $0.20 \mathrm{~m}$. Under higher soil acidity, lime reapplication upon the surface provided a faster reaction. Root growth and grain yields of corn, grown unaffected by water deficits and under high concentrations of organic matter, were not limited by concentrations of $10 \mathrm{mmol}_{\mathrm{C}} \mathrm{dm}^{-3}$ of exchangeableAl in the soil. Therelative root distribution, however, was improved by surfaceliming in compacted soil. Superficial dol omitic limestoneapplication under no-tillagesystem caused an decrease of theK concentration in thecorn leaves, without affecting thegrain yield.
\end{abstract}

Index terms: Zea mays L., dolomiticlimestone, calcium, al uminum, mineral nutrition, root system.

\section{INTRODUÇÃO}

A acidez do solo limita a produção agrícola em consideráveis áreas no mundo, em decorrência da toxidez causada por Al e Mn e da baixa saturação por bases (Coleman \& Thomas, 1967); razão por que as raízes das plantas não crescem bem em solos ácidos (Pavan et al., 1982; Ritchey et al., 1982). A calagem éa prática mais eficiente para el evar o pH, os teores de Ca e a saturação por bases e reduzir Al e Mn trocáveis no solo.

A correção da acidez do solo é muito importante ao adequado desenvolvimento do milho, embora existam materiais genéticos mais tolerantes às condições de acidez (Cantarella, 1993). O aumento do $\mathrm{pH}$ do solo altera a disponibilidade de nutrientes, causando aumentos na absorção de N (Goodroad \& J ellum, 1988), P, K, Ca e Mg (Lutz J r. et al., 1972) pelo milho. Sãovários os trabal hos que demonstram aumentos consideráveis na produção de milho com a aplicação de calcário incorporado ao solo em sistema de preparo convencional (Gonzales-Erico et al., 1979; Camargo et al., 1982; Raij et al., 1983; Ernani et al., 1998). Mesmo os genótipos de milho com tolerância ao Al e que conseguem aprofundar seu sistema radicular em solos ácidos apresentam, normalmente, respostas positivas à cal agem (Raij et al., 1998).

No sistema plantio direto, a correção da acidez do solo é feita mediante aplicação de calcário na superfície, sem incorporação. A viabilidade de aplicação de calcário na superfície, avaliada pelo aumento na produção de grãos de milho nesse sistema decultivo, foi demonstrada por Moschler et al. (1973). A eficiência da calagem superficial na neutralização da acidez do solo causada pela adubação nitrogenada do milho, cultivado no sistema plantio direto, com conseqüente aumento na produção de grãos, também foi observada por Blevins et al. (1978).

Em trabalhos recentes, têm sido verificadas respostas pouco expressivas do milho à aplicação superficial de calcário e altas produtividades da cultura (Pöttker \& Ben, 1998; Caires et al., 1999; Rheinheimer et al., 2000) em sol os áci dos manejados em plantio direto. As explicações para esse comportamento têm sido relacionadas com uma série de fatores inerentes a esse sistema de cultivo.

Os materiais vegetais, mantidos na superfície do solo, podem exercer efeitos positivos sobre a acidez, aumentando o $\mathrm{pH}$ e reduzindo o teor de $\mathrm{Al}$ (Miyazawa et al., 1993). A redução do teor de Al está associada com o aumento do pH e complexação orgânica. O mai or teor de matéria orgânica ea maior concentração de nutrientes na superfície do solo, no sistema plantio direto, são dois fatores que alteram o comportamento do Al em solução. Essas duas características reduzem a atividade do Al e, conseqüentemente, sua toxidez, pela formação de complexos Al-orgânicos e pela maior força iônica da 
solução do sol o(Salet et al., 1994, citados por Anghinoni \& Salet, 1998). O aumento na capacidade de troca de cátions do solo, decorrente do maior teor de matéria orgânica, pode proporcionar concentrações suficientes de cátions trocáveis, mesmo em sol o com alta acidez (Caires et al., 1998). É importante considerar também que, no sistema plantio direto, há mai or umidade nas camadas superficiais (Salton \& Mielniczuk, 1995), graças à cobertura do sol o, que reduz as perdas por evaporação.

Dessa forma, a adequada absorção de nutrientes pelas plantas em condições de sol oáci do em sistema plantio direto (Caires \& Fonseca, 2000) deve ser decorrência de maior umidade disponível no solo. Todavia, faltam informações a respeito das conseqüências da acidez e das alterações químicas do solo proporcionadas pela calagem na superfície sobre o crescimento radicular e sobre a nutrição do milho cultivado em sistema plantio direto.

O presentetrabal ho objetivou estudar a correção da acidez do solo, o crescimento de raízes de milho, a nutrição da planta eseus refl exos sobre a produção de grãos, considerando a aplicação de doses de cal cário, com e sem a sua reaplicação na superfície, em sistema plantio direto.

\section{MATERIAL E MÉTODOS}

O experimento foi realizado no município de Ponta Grossa (PR), Fazenda Estância dos Pinheiros, em um L atossol o Vermel ho distrófico, manejado há 15 anos no sistema plantio direto. Análises químicas (Pavan et al., 1992) e granulométricas (E MBRAPA,
1997) do solo, da camada de $0-0,20 \mathrm{~m}$, realizadas antes da instalação do experimento, revelaram os seguintes resultados: $\mathrm{pH}\left(\mathrm{CaCl}_{2}\right.$ 0,01 mol L-1) 4,5; $58 \mathrm{mmol}_{\mathrm{C}} \mathrm{dm}^{-3}$ de $\mathrm{H}+\mathrm{Al} ; 6 \mathrm{mmol}_{\mathrm{C}} \mathrm{dm}^{-3}$ de $\mathrm{Al}^{3+}$; $16 \mathrm{mmol}_{\mathrm{c}} \mathrm{dm}^{-3}$ de $\mathrm{Ca}^{2+} ; 10 \mathrm{mmol}_{\mathrm{c}} \mathrm{dm}^{-3}$ de $\mathrm{Mg}^{2+}$; $1,4 \mathrm{mmol}_{\mathrm{C}} \mathrm{dm}^{-3}$ de $\mathrm{K}+; 9 \mathrm{mg} \mathrm{dm}^{-3}$ de $\mathrm{P}$ (Mehlich-1); $19 \mathrm{~g} \mathrm{dm}^{-3}$ de C-orgânico e $32 \%$ de saturação por bases e teores de argila, silte e areia, respectivamente, de 220, 195 e $585 \mathrm{~g} \mathrm{~kg}^{-1}$.

O delineamento experimental empregado foi o de blocos completos ao acaso em parcelas subdivididas, com três repetições. Em parcelas de $50,4 \mathrm{~m}^{2}(6,3 \times 8,0 \mathrm{~m})$, foram aplicadas, em julho de 1993, quatro doses de calcário dolomítico na superfície, com $84 \%$ de PRNT: 0, 2, 4 e 6 t ha-1, calculadas visando el evar a saturação por bases da camada de $0-0,20 \mathrm{~m}$ de solo a 50,70 e $90 \%$, respectivamente. Em junho de 2000 , as parcelas foram divididas em duas subparcelas de $25,2 \mathrm{~m}^{2}$ (6,3 x 4,0 m): sem e com a reaplicação de 3 t ha-1 de cal cário dol omítico na superfície, com 89 \% dePRNT. Essa dose foi calculada visando el evar a saturação por bases a $65 \%$ (Caires et al., 2000), considerando a análise química de amostra de solo retirada da camada de 0-0,20 m, do tratamento que havia recebido 4 t ha-1 de calcário, em julho de $1993(\mathrm{pH}$ em $\mathrm{CaCl}_{2}$ 0,01 $\mathrm{mol} \mathrm{L}^{-1}=4,6$, CTC a pH 7,0 = $110,8 \mathrm{mmol}_{\mathrm{c}} \mathrm{dm}^{-3}$ e $41 \%$ de saturação por bases).

Os resultados de análises químicas de amostras de solo, coletadas até à profundidade de 0,20 m, considerando as doses de calcário aplicadas, antes da reaplicação do cal cário, encontram-se no quadro 1. A reaplicação de calcário na superfície foi efetuada com o intuito de aumentar o gradiente dos atributos químicos do solo relacionados com a acidez.

Quadro 1. Resultados de análises químicas de amostras de solo, coletadas em diferentes profundidades, considerando as doses de calcário, antes da reaplicação de calcário na superfície em sistema plantio direto

\begin{tabular}{|c|c|c|c|c|c|c|c|}
\hline Calcário & pH em $\mathrm{CaCl}_{2}$ & $\mathbf{H}+\mathbf{A l}$ & $\mathbf{A l}^{3+}$ & $\mathrm{Ca}^{2+}$ & $\mathbf{M g}^{2+}$ & $\mathbf{K}^{+}$ & Saturação por bases \\
\hline \multirow[t]{2}{*}{$\mathrm{t} \mathrm{ha}^{-1}$} & & 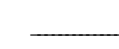 & 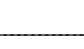 & $\mathrm{mol}_{\mathrm{c}} \mathrm{dn}$ & & ـ & $\%$ \\
\hline & & \multicolumn{5}{|c|}{$0-0,05 \mathrm{~m}$} & \\
\hline \multirow[t]{2}{*}{$\begin{array}{l}0 \\
2 \\
4 \\
6\end{array}$} & $\begin{array}{l}4,1 \\
4,4 \\
4,9 \\
5,1\end{array}$ & $\begin{array}{r}116 \\
85 \\
63 \\
55\end{array}$ & $\begin{array}{r}10 \\
3 \\
1 \\
0\end{array}$ & $\begin{array}{l}15 \\
34 \\
44 \\
48\end{array}$ & $\begin{array}{l}10 \\
12 \\
20 \\
25\end{array}$ & $\begin{array}{l}2,8 \\
2,9 \\
3,0 \\
2,7\end{array}$ & $\begin{array}{l}19 \\
36 \\
51 \\
58\end{array}$ \\
\hline & \multicolumn{7}{|c|}{$0,05-0,10 \mathrm{~m}$} \\
\hline \multirow[t]{2}{*}{$\begin{array}{l}0 \\
2 \\
4 \\
6\end{array}$} & $\begin{array}{l}4,0 \\
4,2 \\
4,5 \\
4,7\end{array}$ & $\begin{array}{r}110 \\
95 \\
76 \\
71\end{array}$ & $\begin{array}{r}10 \\
4 \\
3 \\
2\end{array}$ & $\begin{array}{l}12 \\
23 \\
29 \\
32\end{array}$ & $\begin{array}{l}10 \\
11 \\
13 \\
14\end{array}$ & $\begin{array}{l}2,0 \\
2,0 \\
1,7 \\
1,6\end{array}$ & $\begin{array}{l}18 \\
27 \\
36 \\
40\end{array}$ \\
\hline & \multicolumn{7}{|c|}{$0,10-0,20 \mathrm{~m}$} \\
\hline $\begin{array}{l}0 \\
2 \\
4 \\
6\end{array}$ & $\begin{array}{l}4,0 \\
4,1 \\
4,2 \\
4,3\end{array}$ & $\begin{array}{l}94 \\
92 \\
79 \\
78\end{array}$ & $\begin{array}{r}10 \\
6 \\
5 \\
4\end{array}$ & $\begin{array}{l}11 \\
16 \\
17 \\
18\end{array}$ & $\begin{array}{r}9 \\
9 \\
10 \\
10\end{array}$ & $\begin{array}{l}1,2 \\
0,9 \\
0,8 \\
10\end{array}$ & $\begin{array}{l}18 \\
22 \\
26 \\
27\end{array}$ \\
\hline
\end{tabular}


No período compreendido entre novembro de 1993 e maio de 2000, foram utilizados na rotação de culturas: soja (1993/1994), ervilhaca + aveia preta (inverno/1994), milho (1994/1995), pousio (inverno/ 1995), soja (1995/1996), trigo (inverno/1996), soja (1996/1997), triticale (inverno/1997), soja (1997/1998), aveia preta (inverno/1998), soja (1998/1999), aveia preta (inverno/1999) e soja (1999/2000).

A semeadura do mil ho foi feita em 30 de setembro de 2000, após o cultivo de aveia preta, na densidade de cinco sementes por metro linear e espaçamento de $0,9 \mathrm{~m}$ entre as linhas. Foi utilizado o híbrido AG 9090, da Agroceres, de tol erância intermediária ao Al (Furlani \& Duarte, 2001). A adubação básica utilizada na semeadura foi de $330 \mathrm{~kg} \mathrm{ha}^{-1}$ da fórmula 10-20-20 e, em cobertura, foram aplicados $275 \mathrm{~kg} \mathrm{ha}^{-1}$ da fórmula 36-00-12, logo após a emissão da quarta folha. A temperatura média do ar e a precipitação pluvial durante o ciclo da cultura foram, respectivamente, de $21^{\circ} \mathrm{C}$ e $1.304 \mathrm{~mm}$.

No início do florescimento da cultura, foram realizadas amostragens de fol has, plantas e raízes. As amostras de fol has foram col etadas em 30 plantas de cada subparcela, retirando-se a folha imediatamente abaixo e oposta à espiga, para análise química dos teores de N, P, K, Ca e Mg, de acordo com os métodos descritos por Malavol ta et al . (1997). Foram retiradas cinco plantas, somente a parte aérea, ao acaso de cada subparcela, para avaliação da altura e da produção de matéria seca. As amostras de raízes foram coletadas por meio detrado cilíndrico, com $3,5 \mathrm{~cm}$ de diâmetro, em quatro profundidades $(0-0,10,0,10-0,20,0,20-0,40$ e 0,40$0,60 \mathrm{~m})$, retirando-se seis subamostras, sendo três na linha de semeadura e três nas entrelinhas, eqüidistantes $0,10 \mathrm{~m}$ da planta, para compor uma amostra composta em cada subparcela. As raízes foram separadas do solo por dispersão em água, através de peneira de $0,5 \mathrm{~mm}$. O comprimento de raízes foi estimado pelo método deTennant (1975), e o raio médio, segundo Schenk \& Barber (1979).

Após a maturação, o milho foi col hido e trilhado, sendo então determinada a produção de grãos a $13 \%$ de umidade. Foram col hidas as cincolinhas centrais por 3,0 m de comprimento em cada subparcela, tendo sido desprezado 0,5 m de cada extremidade.

Após a col heita, foram col etadas amostras de solo, retirando-se, ao acaso, 12 subamostras por subparcela, para compor uma amostra composta das camadas de 0-0,05, 0,05-0,10 e 0,10-0,20 m, e cinco subamostras, para as camadas de 0,20-0,40 e 0,40$0,60 \mathrm{~m}$ de profundidade. As amostras até à profundidade de $0,20 \mathrm{~m}$ foram retiradas com trado calador, e as de 0,20-0,60 m, com trado holandês, tendo sido determinados o $\mathrm{pH}, \mathrm{H}+\mathrm{Al}, \mathrm{Al}^{3+}, \mathrm{Ca}^{2+}$, $\mathrm{Mg}^{2+}, \mathrm{K}^{+}, \mathrm{P}$ (Mehlich-1) e C-orgânico, de acordo com os métodos descritos em Pavan et al. (1992).

A resistência do solo à penetração foi avaliada por meio de penetrômetro de impacto, após a colheita, em 15 pontos ao acaso dentro da área experimental, até à profundidade de 0,60 m, conforme o método de Stolf (1991).

Os resultados foram submetidos às análises de variância e de regressão polinomial. Foram ajustadas equações de regressão aos dados obtidos de acor do com as doses de cal cário, adotando-se como critério para escol ha do modelo a magnitude dos coeficientes de determinação significativos a $5 \%$. Os efeitos da reapl icação de cal cári o foram comparados pelo teste $F$.

\section{RESULTADOS E DISCUSSÃO}

A análise de variância dos resultados de análise química do solo, nas cinco profundidades estudadas, mostrou interação significativa de doses e reaplicação de calcário para saturação por bases e cál cio trocável, na camada de 0-0,05 m, e alumínio trocável, nas camadas de 0-0,05 e 0,05-0,10 m. A ausência de interação nas camadas mais profundas do solo mostra que as modificações nos atributos químicos do solo relacionados com acidez, dependendo das doses de calcário, foram semelhantes, na presença ou ausência dereaplicação de cal cário na superfície.

A aplicação de doses de calcário na superfície, após 92 meses, proporcionou aumentos significativos no pH e na saturação por bases do solo, nas cinco profundidades estudadas (Figura 1). Os efeitos da reaplicação superficial de calcário sobre tais variáveis, após nove meses, foram significativos até à profundidade de 0,20 m, embora tenham ocorrido em mai or magnitude nas camadas mais superficiais (0-0,05 e 0,05-0,10 m).

A interação significativa entre os tratamentos de calagem para saturação por bases, na camada superficial do solo (0-0,05 $\mathrm{m})$, revelou que a reaplicação de calcário na superfície aumentou significativamente $(P<0,01)$ a saturação por bases do sol o somente nas doses 0 e $2 \mathrm{t}$ ha-1 de cal cário, de $18 \%$ para $41 \%$ ede $34 \%$ para $50 \%$, respectivamente. Comportamento semelhante foi observado para opH em $\mathrm{CaCl}_{2} 0,01 \mathrm{~mol} \mathrm{~L}^{-1}$, na camada de 0-0,05 m, apesar de a interação entre doses e reaplicação de cal cário para essa variável não ter sido significativa. Esses resultados mostram que a reação do cal cário aplicado na superfície, em sistema plantio direto, é influenciada pela acidez do solo na camada superficial, sendo mais rápida ou mais lenta, respectivamente, em condições de maior ou menor acidez.

Consi derando a média de doses de cal cário, a sua reaplicaçãona superfícieaumentou significativamente o $\mathrm{pH}$ em $\mathrm{CaCl}_{2} 0,01 \mathrm{~mol} \mathrm{~L}^{-1}(\mathrm{P}<0,01)$ de 4,5 para 4,9 e 4,4 para 4,5, e a saturação por bases do solo de $28 \%$ para $36 \%(P<0,01)$ e $21 \%$ para $25 \%(P<0,05)$, 
respectivamente, nas camadas de 0,05-0,10 e 0,10$0,20 \mathrm{~m}$. Tendo em vista o tempo de reação do cal cário reaplicado na superfície, de apenas nove meses, podem ser consideradas satisfatórias as alterações ocorridas no pH e na saturação por bases do solo com essa aplicação.

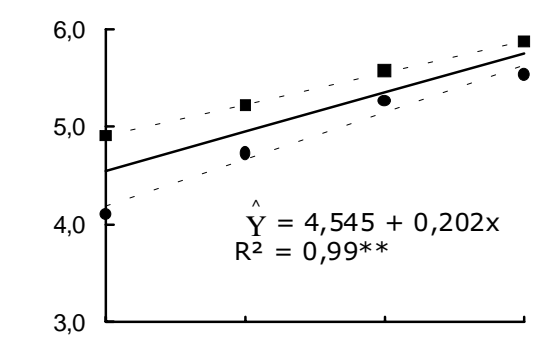

(a)
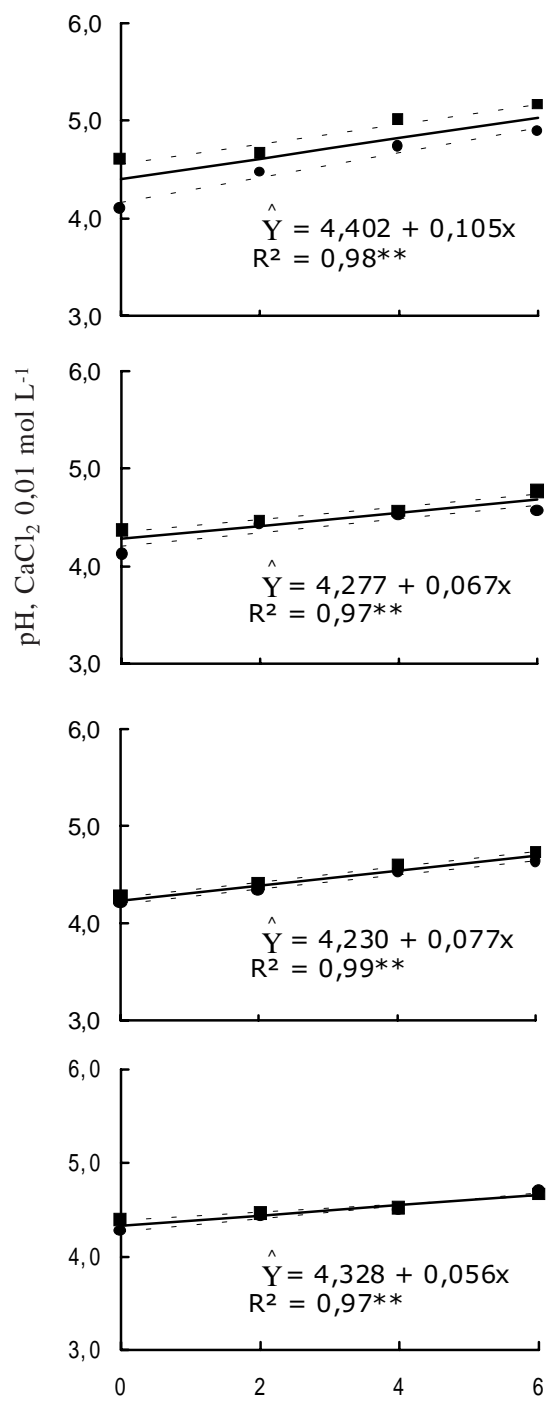

(b)

(c)

(d)

(e)
Houve aumento do Ca e redução do Al trocável do solo, nas cinco profundidades estudadas, considerando a aplicação de doses de cal cário na superfície, após 92 meses (Figura 2). A reaplicação superficial de calcário, após nove meses, proporcionou alterações significativas nos teores de
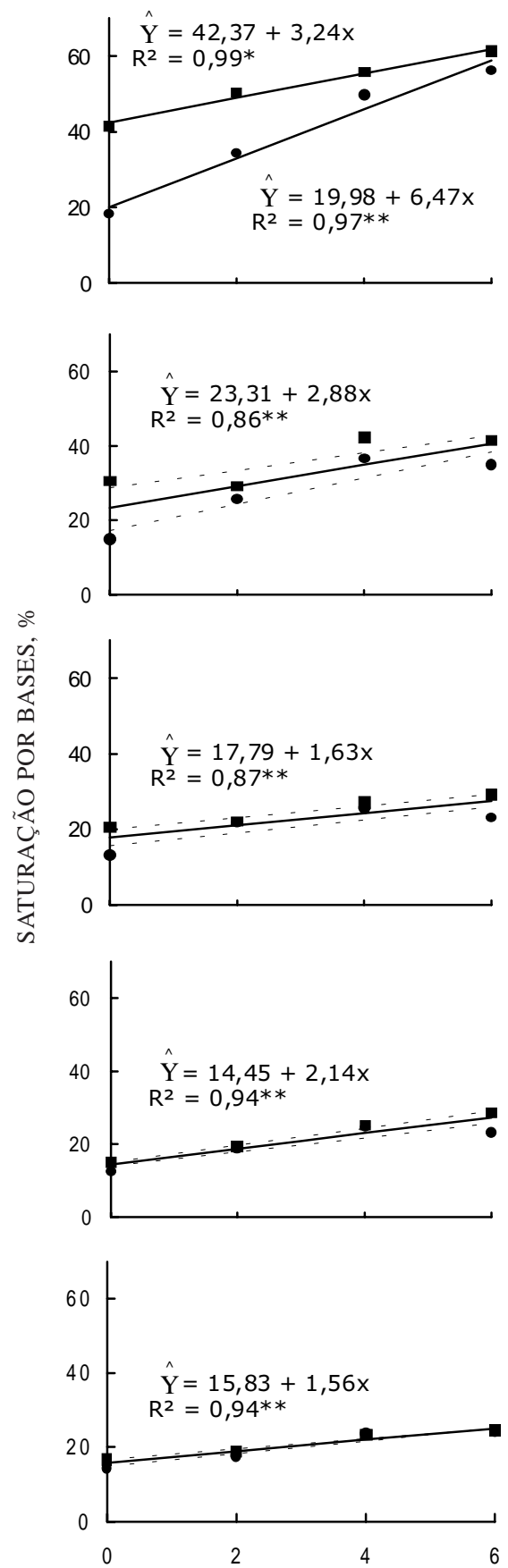

CALCÁRIO, t ha-1

Figura 1. Alterações do $\mathrm{pH}$ em $\mathrm{CaCl}_{2} 0,01 \mathrm{~mol} \mathrm{~L}^{-1}$ e da saturação por bases, em diferentes profundidades do solo: 0-0,05 m (a), 0,05-0,10 m (b), 0,10-0,20 m (c), 0,20-0,40 m (d) e 0,40-0,60 m (e), considerando as doses de calcário na superfície, após 92 meses, $\operatorname{sem}(\bullet)$ e com $(\square)$ a reaplicação de calcário, após nove meses, em sistema plantio direto. * =significativo $\mathrm{P}<0,05 \mathrm{e} * *=$ significativo $\mathrm{P}<0,01$. 
Ca e Al trocáveis do solo, até à profundidade de $0,20 \mathrm{~m}$. Mesmo assim, de forma semel hante ao ocorrido para o pH esaturação por bases, tais efeitos sobre o Ca e o Al trocável do solo foram mais acentuados nas camadas mais superficiais $(0-0,05$ e 0,05-0,10 m).

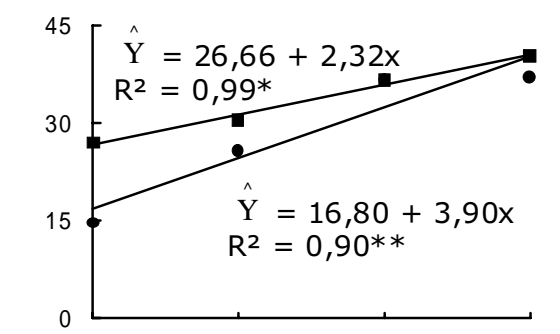

(a)

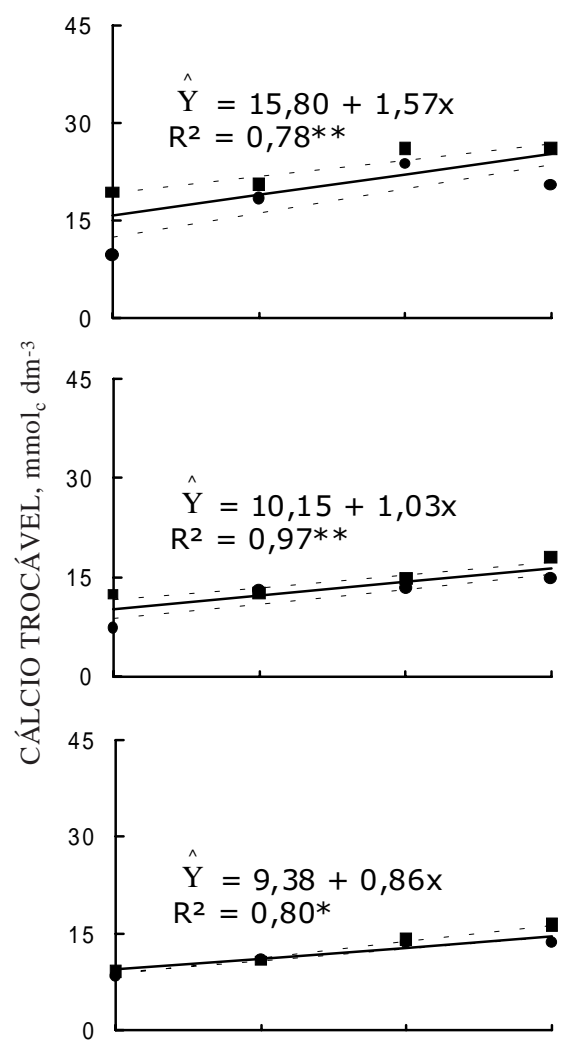

(b)

(c)

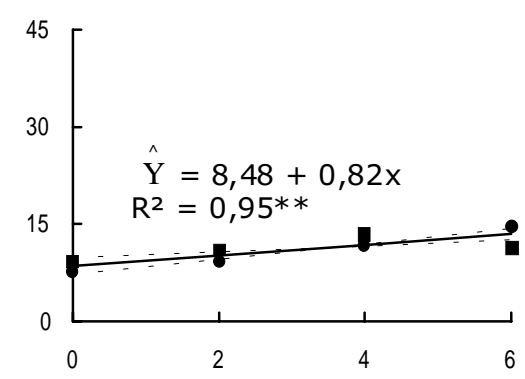

(d)

(e)
As interações entre doses e reaplicação de cal cário para Ca trocável, na profundidade de 0-0,05 m, eAl trocável, nas profundidades de 0-0,05 e 0,05-0,10 m, revelaram efeitos significativos da reaplicação $(\mathrm{P}<0,01)$ somente na dose $0 \mathrm{t} \mathrm{ha}^{-1}$ de calcário. Nessa condição de maior acidez do solo, a reaplicação de
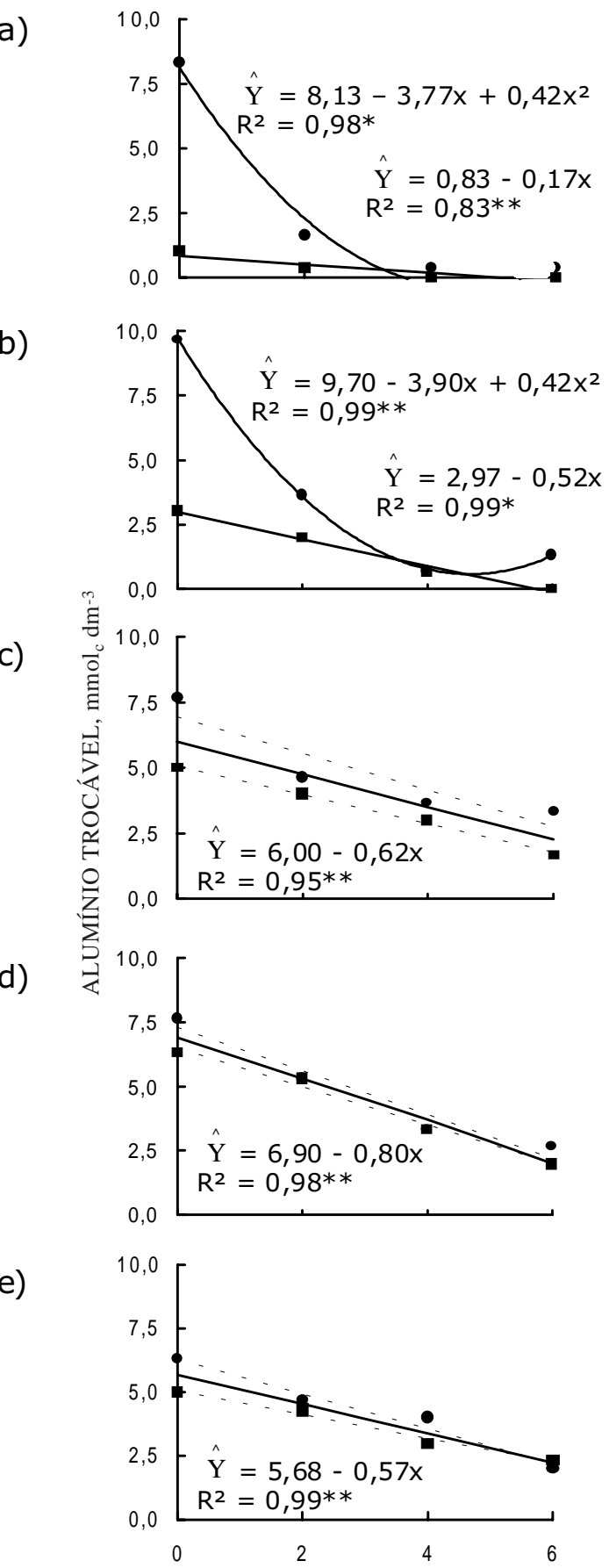

CALCÁRIO, $\mathrm{t} \mathrm{ha}^{-1}$

Figura 2. Alterações dos teores de Ca e Al trocáveis, em diferentes profundidades do solo: 0-0,05 m (a), 0,05-0,10 m (b), 0,10-0,20 m (c), 0,20-0,40 m (d) e 0,40-0,60 m (e), considerando as doses de calcário na superfície, após 92 meses, sem $(\bullet)$ e com $(\bullet)$ a reaplicação de calcário, após nove meses, em sistema plantio direto. $*=$ significativo $\mathrm{P}<0,05 \mathrm{e}^{* *}=$ significativo $\mathrm{P}<0,01$. 
calcário na superfície proporcionou aumento do Ca trocável de 15 para $27 \mathrm{mmol}_{\mathrm{c}} \mathrm{dm}^{-3}(0-0,05 \mathrm{~m})$, e redução do Al trocável de 8 para $1 \mathrm{mmol}_{\mathrm{c}} \mathrm{dm}^{-3}$ $(0-0,05 \mathrm{~m})$ e de 10 para $3 \mathrm{mmol}_{\mathrm{c}} \mathrm{dm}^{-3}(0,05-0,10 \mathrm{~m})$.

Considerando a média de doses de cal cário, a sua reaplicação na superfície aumentou significativamente o Ca trocável $(P<0,05)$ de 18 para 23 e 12 para $14 \mathrm{mmol}_{\mathrm{C}} \mathrm{dm}^{-3}$, respectivamente, nas camadas de $0,05-0,10$ e $0,10-0,20 \mathrm{~m}$, e reduziu o Al trocável do solo, na camada de $0,10-0,20 \mathrm{~m}$, de 5 para $3 \mathrm{mmol}_{\mathrm{C}} \mathrm{dm}^{-3}(\mathrm{P}<0,01)$.

Os resultados da calagem na neutralização da acidez de subsolos são discordantes na literatura. Alguns trabalhos mostraram que o calcário não se movimenta para camadas mais profundas do solo (Gonzales-Erico et al., 1979; Ritchey et al., 1980; Pavan et al., 1984), enquanto outros revelaram consideráveis aumentos no pH e nos teores de Ca e Mg trocáveis abaixo da região de aplicação do calcário, tanto em áreas de cultivos anuais preparadas convencional mente(Quaggio et al., 1993; Oliveira et al., 1997; Caires \& Rosolem, 1998) quanto em áreas de cultivos perenes estabel ecidos (Chaves et al., 1984; Pavan, 1994).

A eficiência da aplicação superficial de calcário na redução da acidez de camadas superficiais e do subsolo, no sistema plantio direto, foi demonstrada nos trabalhos de Oliveira \& Pavan (1996) e Caires et al. (2000). A correção da acidez de subsolos pela calagem na superfície em tal sistema de cultivo tem sido atribuída não só à formação e movimentação descendente de $\mathrm{Ca}\left(\mathrm{HCO}_{3}\right)_{2}$ e $\mathrm{Mg}\left(\mathrm{HCO}_{3}\right)_{2}$ para camadas mais profundas de solo (Costa, 2000), mas também ao desl ocamento mecânico de partículas de calcário por meio de canais formados por raízes mortas, mantidos intactos em razão da ausência de preparo do solo (Pavan, 1994), e ao manejo de resíduos orgânicos de plantas (Miyazawa et al., 1996; Ziglio et al., 1999).

Além disso, muitos exemplos na literatura têm comprovado a correção da acidez de subsolos pela adição de calcário e fertilizantes nitrogenados (Pearson et al., 1962; Adams et al., 1967; Weir, 1975). É importante destacar, no presente estudo, que as plantas desenvol veram-se em variadas condições de acidez do solo (Figuras 1 e2), conformeera esperado e pretendido.

A análise de variância não revelou interação significativa entre doses e reaplicação de calcário para nenhum dos parâmetros avaliados na planta. Por essa razão, as respostas do milho à aplicação de doses e à reaplicação de cal cário foram anal isadas, separadamente, por meio das médias dos tratamentos.

O crescimento radicular do milho até à profundidade de 0,60 $\mathrm{m}$ não foi influenciado significativamente pelos tratamentos de calagem, encontrando-se valores médios de comprimento de raízes por superfície de solo, em $\mathrm{cm} \mathrm{cm}^{-2}$, de 61,6 , $60,3,56,2$ e 59,9, respectivamente, para as doses 0,2 4 e 6 t ha $^{-1}$ de calcário, e de 58,3 e 60,7, para os tratamentos sem e com a reaplicação de calcário. Esses resultados mostram que a concentração de $10 \mathrm{mmol}_{\mathrm{C}} \mathrm{dm}^{-3}$ deAl trocável no solo (Quadro 1) não causou restrição ao crescimento radicular do milho cultivado no sistema plantio direto.

O comprimento relativo de raízes foi linearmente reduzido na camada superficial do solo $(0-0,10 \mathrm{~m})$ e aumentado no subsolo (0,20-0,60 m) com a aplicação de doses de cal cário, mostrando que as raízes ficaram mais concentradas na superfície em condições de maior acidez (Figura 3). A reaplicação de cal cário aumentou a concentração do comprimento radicular na profundidade de 0,10-0,20 m.

O raio médio de raízes de milho não foi alterado significativamente pelas doses e reaplicação de calcário na superfície (F igura 4). No entanto, na camada de 0,10-0,20 m, o raio médio das raízes foi maior do que na camada superficial (0-0,10 m), em conseqüência de mai or compactação do sol o naquela profundidade, verificada pela maior resistência ao penetrômetro (Figura 4). De acordo com Rosolem et al. (1994), a calagem pode exercer efeito positivo sobre os parâmetros morfológicos das raízes de milho, avaliados em camada de solo compactada. I sso explica o maior crescimento relativo de raízes na profundidade de 0,10-0,20 m, com a reaplicação de calcário na superfície (Figura 3), pois, nessa camada de solo, o comprimento relativo de raízes esteve relacionado $(P<0,05)$ positivamente com o Ca trocável $(r=0,48)$ e negativamente com o Al trocável $(r=-0,47)$. Portanto, a distribuição relativa de raízes de milho, cultivado em sistema plantio direto, foi favorecida pela calagem superficial na presença de solo compactado.

A aplicação de doses de calcário aumentou os teores de $\mathrm{Ca}$ e $\mathrm{Mg}$ e reduziu a concentração de K nas folhas de milho, enquanto a reaplicação de calcário não alterou significativamente os teores foliares de nutrientes (Quadro 2). O K trocável no solo não apresentou alteração significativa, considerando os tratamentos de calagem, nas cinco profundidades estudadas. Os teores médios de K no solo, em $\mathrm{mmol}_{\mathrm{c}} \mathrm{dm}^{-3}$, foram de 2,1 (0-0,05 m), 1,2 $(0,05-0,10 \mathrm{~m}), 0,9(0,10-0,20 \mathrm{~m}), 0,8(0,20-0,40 \mathrm{~m}) \mathrm{e}$ $0,6(0,40-0,60 \mathrm{~m})$. A redução da concentração de $\mathrm{K}$ nas fol has de milho esteve relacionada com o aumento da relação $\mathrm{Ca}+\mathrm{Mg} / \mathrm{K}$ no solo, na profundidade de $0-0,20 \mathrm{~m}$, em decorrência da calagem (Figura 5).

As relações obtidas entre a concentração de $\mathrm{K}$ e a de $\mathrm{Ca}, \mathrm{Mg}$ e $\mathrm{Ca} / \mathrm{Mg}$ no tecido foliar de milho (Figura 6) mostram que a redução do teor foliar de $\mathrm{K}$ foi acompanhada por aumento dos teores de Ca e $\mathrm{Mg}$ nas fol has, evidenciando efeito substitutivo de 


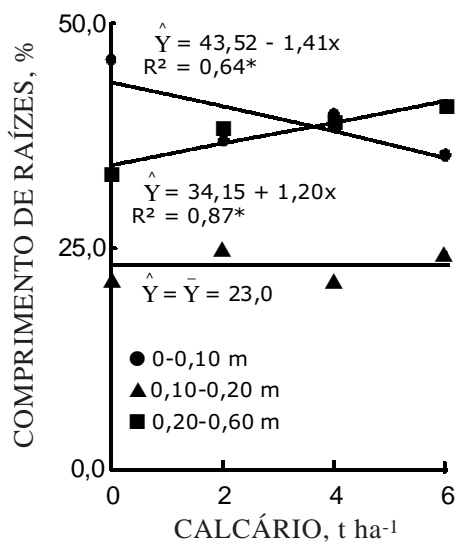

(a)

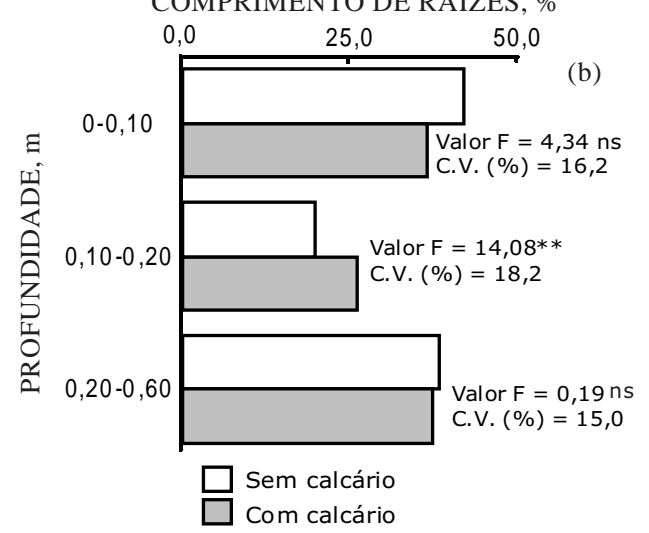

Figura 3. Distribuição relativa do comprimento de raízes de milho, em diferentes profundidades do solo, considerando a aplicação de doses (a) e a reaplicação (b) de calcário na superfície em sistema plantio direto. (a: médias de dois tratamentos de calagem e três repetições; b: médias de quatro doses de calcário e três repetições). ns = não-significativo, * = significativo $P<0,05 e^{* *}=$ significativo $P<0,01$.

K por Ca e Mg. A concentração de K no tecido foliar aumentou linearmente com o acréscimo da relação $\mathrm{Ca} / \mathrm{Mg}$ nas fol has, mostrando o antagonismo entre Mg e K. Resultados semel hantes relacionados com a influência do Ca e do $\mathrm{Mg}$ sobre a absorção de K pelo mil ho foram obtidos em outros trabal hos (Loué, 1963; Andreotti et al., 2000).

Com respeito à composi ção do tecido foliar, a soma de $\mathrm{Ca}, \mathrm{Mg}$ e K permanece constante, sendo de cerca de $1.000 \mathrm{mmol}_{\mathrm{c}} \mathrm{kg}^{-1}$ (Viets et al., 1954, citados por Büll, 1993). No presente trabalho, a soma desses cátions nas fol has, considerando as doses de cal cário aplicadas, esteve próxima desse valor, variando de 964 a $1.094 \mathrm{mmol}_{\mathrm{c}} \mathrm{kg}^{-1}$. Sendo assim, o cál culo das percentagens de $\mathrm{K}$, Ca e Mg dentro da soma dos cátions, praticamente constante, é válido para estudar o equilíbrio dos nutrientes catiônicos na cultura do milho (Loué, 1963). Considerando a soma dos três cátions no tecido foliar, foram observados

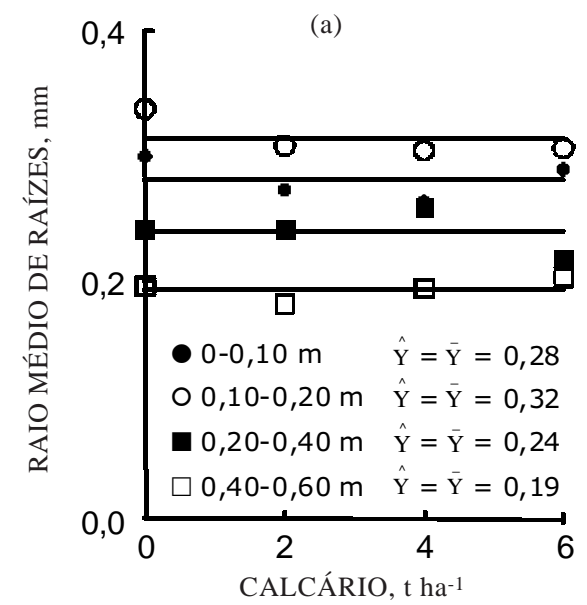

(b)

RAIO MÉDIO DE RAÍZES, mm

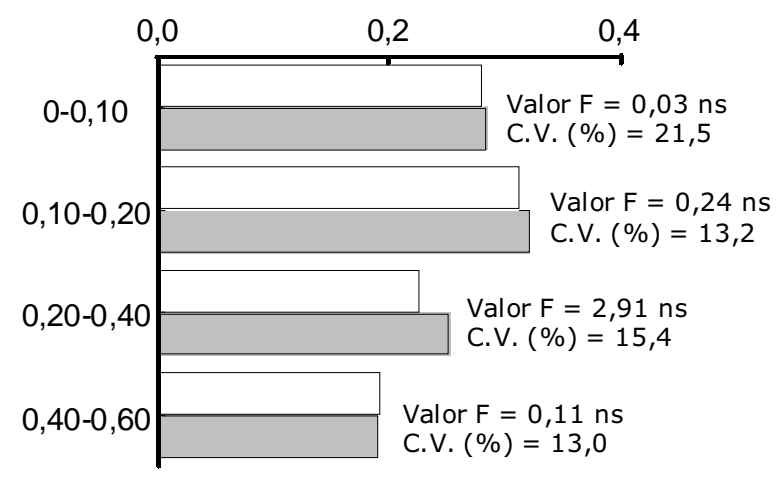

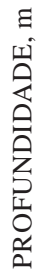

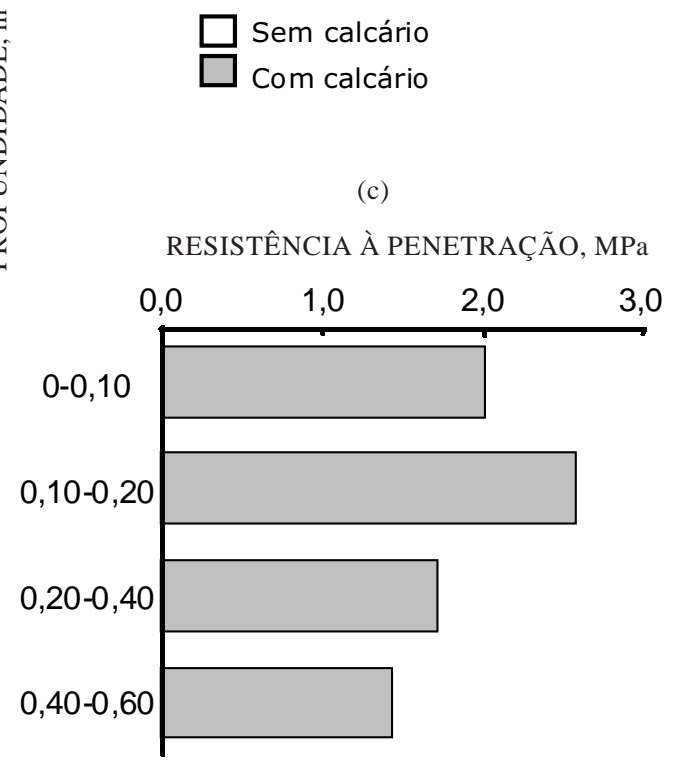

Figura 4. Raio médio de raízes de milho, considerando a aplicação de doses (a) e a reaplicação (b) de calcário na superfície em sistema plantio direto, e resistência do solo à penetração (c), em diferentes profundidades. (a: médias de dois tratamentos de calagem e três repetições; b: médias de quatro doses de calcário e três repetições). ns = não-significativo. 
Quadro 2. Concentração de nutrientes nas folhas de milho, considerando as doses e a reaplicação de calcário na superfície em sistema plantio direto

\begin{tabular}{|c|c|c|c|c|c|}
\hline Tratamento & $\mathbf{N}$ & $\mathbf{P}$ & $\mathbf{K}$ & $\mathrm{Ca}$ & Mg \\
\hline \multirow{2}{*}{\multicolumn{6}{|c|}{ Calcário, t ha-1 }} \\
\hline & & & & & \\
\hline 0 & 30,9 & 3,0 & 20,5 & 5,8 & 1,8 \\
\hline 2 & 30,5 & 3,0 & 18,7 & 6,7 & 3,1 \\
\hline 4 & 31,4 & 3,0 & 16,6 & 6,8 & 3,4 \\
\hline 6 & 30,3 & 3,1 & 15,6 & 7,4 & 3,9 \\
\hline Efeito & ns & ns & $L^{* *}$ & $\mathrm{~L}^{* *}$ & $\mathrm{~L}^{* *}$ \\
\hline C.V. (\%) & 4,8 & 4,9 & 13,7 & 10,4 & 20,7 \\
\hline \multicolumn{6}{|c|}{ Reaplicação de calcário } \\
\hline Sem calcário & 30,6 & 3,0 & 18,0 & 6,6 & 2,9 \\
\hline Com calcário & 31,0 & & 17,7 & & 3,2 \\
\hline Valor $F$ & $0,56 \mathrm{~ns}$ & $2,58 \mathrm{~ns}$ & $0,11 \mathrm{~ns}$ & $1,92 \mathrm{~ns}$ & $0,92 \mathrm{~ns}$ \\
\hline C.V. (\%) & 4,5 & 4,8 & 12,3 & 5,6 & 17,5 \\
\hline
\end{tabular}

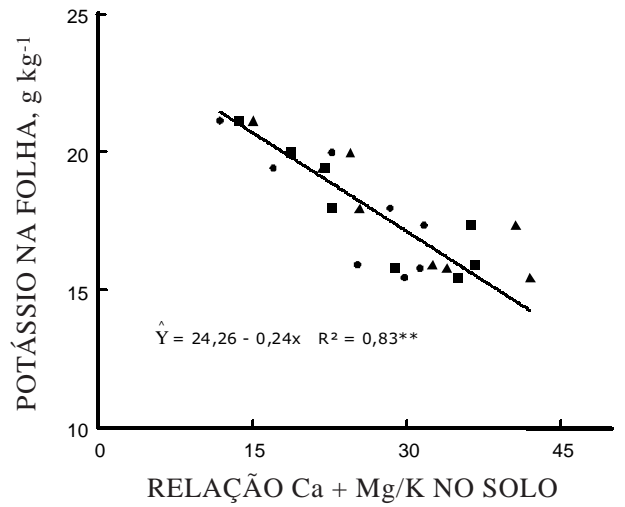

Figura 5. Concentração de potássio no tecido foliar de milho, considerando a relação $\mathrm{Ca}+\mathrm{Mg} / \mathrm{K}$ no solo, na profundidade de $0-0,20 \mathrm{~m}(\bullet=0-0,05 \mathrm{~m}$, $\Delta=0,05-0,10 \mathrm{~m}$ e $\square=0,10-0,20 \mathrm{~m})$. $* *=$ significativo $P<0,01$.
$54 \%$ de K, 30 \% de Ca e $16 \%$ de $\mathrm{Mg}$, na ausência de calagem, e $36 \%$ de K, $34 \%$ de Ca e $30 \%$ de $\mathrm{Mg}$, com a utilização da maior dose de calcário ( $\left.6 \mathrm{t} \mathrm{ha}^{-1}\right)$. Tendo em vista que a relação nutricional ótima para o milho corresponde a equilíbrios entre 60-28-12 e 68-22-10 (K-Ca-Mg, em \%) no tecido foliar (Loué, 1963), percebe-se que a calagem proporcionou desequilíbrios nutricionais de cátions na planta, principalmente entre MgeK.

A altura das plantas demilhoaumentou, de forma quadrática, com a aplicação de doses de cal cário e não foi influenciada pela reaplicação de cal cário no solo (Quadro 3). De acordo com a equação de regressão ajustada ( $\left.\hat{Y}=2,585+0,090 x-0,013 x^{2}, R^{2}=0,99\right)$, a maior altura das plantas seria obtida com a dose de 3,5 t ha-1 decalcário. Deve-se destacar queas plantas apresentaram, no início de seu crescimento, menor altura e clorose nas folhas (sintomas visuais),
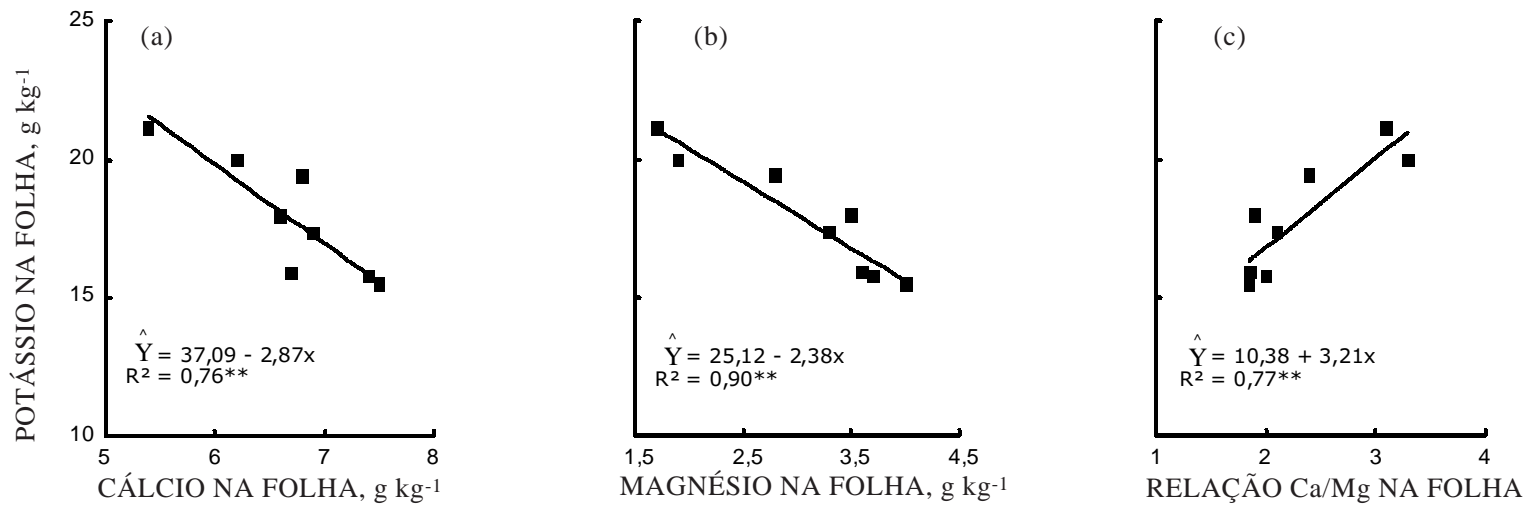

Figura 6. Relações entre a concentração de potássio e a de cálcio (a), magnésio (b) e Ca/Mg no tecido foliar de milho. $* *=$ significativo $\mathrm{P}<0,01$. 


\section{Quadro 3. Altura das plantas, produção de matéria seca da parte aérea e de grãos de mi lho, consi derando as doses e a reaplicação de calcário na superfície em sistema plantio dir reto}

\begin{tabular}{cccc}
\hline Tratamento & Altura da planta & Matéria seca da parte aérea & Produção de grãos \\
\cline { 3 - 4 } & $\mathrm{m}$ & & \\
Calcário, t ha-1 & & $\mathrm{kg} \mathrm{ha}^{-1}$ & \\
0 & 2,58 & 8.808 & 9.490 \\
2 & 2,72 & 8.773 & 9.485 \\
4 & 2,74 & 9.470 & 9.639 \\
6 & 2,68 & 9.253 & $\mathrm{n}$ \\
Efeito & $\mathrm{Q}^{*}$ & 11,4 & $\mathrm{~ns}$ \\
C.V. (\%) & 4,0 & & 3,8 \\
Reaplicação de calcário & & 8.970 & 9.456 \\
Sem calcário & 2,68 & 9.182 & 9.597 \\
Com calcário & 2,68 & $0,80^{\mathrm{ns}}$ & $0,75^{\mathrm{ns}}$ \\
Valor F & $0,10^{\text {ns }}$ & 6,4 & 4,1 \\
C.V. (\%) & 1,7 & &
\end{tabular}

$\overline{\mathrm{Q}}=$ efeito quadrático por regressão polinomial; ns = não-significativo; * = significativo $\mathrm{P}<0,05$.

somente em condições de maior acidez do solo (ausência decalagem). Mesmoassim, os tratamentos de calagem não proporcionaram alterações significativas na produção de matéria seca da parte aérea, avaliada no início do florescimento da cultura, e no rendimento de grãos de milho (Quadro 3). A produção média do experimento foi da ordem de $9.500 \mathrm{~kg} \mathrm{ha}^{-1}$ de grãos de milho.

Em solos ácidos manejados em plantio direto no sul do Brasil, altas produtividades de milho têm sido obti das na ausência de cal cário (Pöttker \& Ben, 1998; Caires et al., 1999; Rheinheimer et al., 2000) e atribuídas ao menor efeito tóxico doAl, à relação de substituição de calcário pelo P (Ernani et al., 2000) ou à disponi bilidade suficiente de Ca e M g trocáveis, graças à el evada capacidade de troca de cátions decorrente do alto teor de matéria orgânica (Caires et al., 1998).

No presente trabal ho, não houve limitação de $P$ no solo para o desenvolvimento do milho. O P do solo (Mehlich-1) não foi al terado pela calagem, tendo sido encontrados teores médios de 12,5, 7,7 e $2,4 \mathrm{mg} \mathrm{dm}^{-3}$, respectivamente, nas camadas de 0 $0,05,0,05-0,10$ e 0,10-0,20 m. O solo tinha teores suficientes de Ca e Mg trocáveis, e a concentração de $10 \mathrm{mmol}_{\mathrm{C}} \mathrm{dm}^{-3}$ de Al trocável (Quadro 1 ) não limitou o crescimento radicular e a produção de milho. Tal ocorrência pode ser devida a duas causas principais: teores de matéria orgânica e condições de precipitação pluvial. A primeira causa diz respeito aos el evados teores de matéria orgânica do solo (48, 36 e $30 \mathrm{~g} \mathrm{dm}^{-3}$, respectivamente, nas profundidades de $0-0,05,0,05-0,10$ e 0,10-0,20 m). O Al pode formar complexos com ligantes orgânicos de baixo peso molecular, provenientes de resíduos vegetais
(Miyazawa et al., 1993), ou com ácidos fúlvicos da matéria orgânica estável, ocorrendo redução de sua atividade na solução do solo (Bloom et al., 1979). Produção de milho superior a $7.000 \mathrm{~kg} \mathrm{ha}^{-1}$, na ausência de calagem ( $\mathrm{pH}$ em água de 4,7, Al trocável de $33 \mathrm{mmol}_{\mathrm{c}} \mathrm{dm}^{-3}$ e $56 \%$ de saturação por Al), também foi obtida em solo com alto teor de matéria orgânica, no sistema de preparo convencional (Ernani et al., 1998).

A segunda causa está relacionada com as excel entes condições de precipitação pluvial que ocorreram durante o ciclo da cultura no campo, considerando quea toxidez deAl para o mil hoémais acentuada quando a disponi bilidade de água no sol o é baixa (Freire, 1984).

\section{CONCLUSÕES}

1. A calagem na superfície, em sistema plantio direto, apresentou eficiência na correção da acidez de camadas superficiais e do subsolo, mas a reação do cal cário aplicado superficial mentefoi mais rápida em condições de maior acidez do solo.

2. $\mathrm{Na}$ ausência de déficit hídrico, não houve limitação do crescimento radicular e da produção de milho para concentração de $10 \mathrm{mmol}_{\mathrm{c}} \mathrm{dm}^{-3}$ de Al trocável em solo com el evado teor de matéria orgânica, mas a calagem na superfície melhorou a distribuição relativa de raízes na presença de solo compactado.

3. A aplicação superficial de cal cário dolomítico em solo ácido com teores suficientes de Ca, Mg e K 
trocáveis proporcionou substituição de $\mathrm{K}$ por $\mathrm{Ca}$ e, principalmente, $\mathrm{Mg}$ no tecido foliar do milho, sem causar conseqüências na produção de grãos.

\section{LITE RATURA CITADA}

ADAMS, F.; WHITE, A.W. \& DAWSON, R.N. Influence of lime sources and rates on Coastal bermudagrass production, soil profile reaction, exchangeable Ca and Mg. Agron. J ., 59:147149, 1967.

ANDREOTTI, M.; SOUZA, E.C.A.; CRUSCIOL, C.A.; RODRIGUES, J.D. \& BÜLL, L.T. Produção de matéria seca e absorção de nutrientes pelo milho em razão da saturação por bases e da adubação potássica. Pesq. Agropec. Bras., $35: 2437-3446,2000$

ANGHINONI, I. \& SALET, R.L. Amostragem do solo e as recomendações de adubação e calagem no sistema plantio direto. In: NUERNBERG, N.J., ed. Conceitos e fundamentos do sistema plantio direto. Lages, Sociedade Brasileira de Ciência do Solo, Núcleo Regional Sul, 1998. p.27-52.

BLEVINS, R.L.; MURDOCK, L.W. \& THOMAS, G.W. Effect of lime application on no-tillage and conventionally tilled corn. Agron. J., 70:322-326, 1978.

BLOOM, P.R.; McBRIDE, M.B. \& WEAVER, R.M. Aluminum organic - matter in acid Soils - buffering and solution aluminum activity. Soil Sci. Soc. Am. J., 43:488-493, 1979.

BÜLL, L.T. Nutrição mineral do milho. In: BÜLL, L.T. \& CANTARELLA, H., eds. Cultura do milho: fatores que afetam a produtividade. Piracicaba, POTAFOS, 1993. p.63145.

CAIRES, E.F. \& FONSECA, A.F. Absorção de nutrientes pela soja cultivada no sistema de plantio direto em função da calagem na superfície. Bragantia, 59:213-220, 2000.

CAIRES, E.F. \& ROSOLEM, C.A. Correção da acidez do solo e desenvolvimento do sistema radicular do amendoim em função da calagem. Bragantia, 57:175-184, 1998.

CAIRES, E.F.; BANZATTO, D.A. \& FONSECA, A.F. Calagem na superfície em sistema plantio direto. R. Bras. Ci. Solo, 24:161-169, 2000.

CAIRES, E.F.; CHUEIRI， W.A.; MADRUGA， E.F. \& FIGUEIREDO, A. Alterações de características químicas do solo e resposta da soja ao calcário e gesso aplicados na superfície em sistema de cultivo sem preparo do solo. R. Bras. Ci. Solo, 22:27-34, 1998.

CAIRES, E.F.; FONSECA, A.F.; MENDES, J .; CHUEIRI, W.A. \& MADRUGA, E.F. Produção de milho, trigo e soja em função das alterações das características químicas do solo pela aplicação de calcário e gesso na superfície, em sistema de plantio direto. R. Bras. Ci. Solo, 23:315-327, 1999.

CAMARGO,A.P.; RAIJ , B. van; CANTARELLA, H.; ROCHA,T.R.; NAGAI, V. \& MASCARENHAS, H.A.A. Efeito da calagem nas produções de cinco cultivos de mil ho seguidos deal godão e soja. Pesq. Agropec. Bras., 17:1007-1012, 1982.
CANTARELLA, H. Calagem e adubação do milho. In: BÜLL, L.T. \& CANTARELLA, H., eds. Cultura do milho: fatores que afetam a produtividade. Piracicaba, POTAFOS, 1993. p.147-196.

CHAVES, J.C.D.; PAVAN, M.A. \& IGUE, K. Resposta do cafeeiro à calagem. Pesq. Agropec. Bras., 19:573-582, 1984.

COLEMAN, N.T. \& THOMAS, G.W. The basic chemistry of soil acidity. In: PEARSON, R.W. \& ADAMS, F., eds. Soil acidity and liming. Madison, American Society of Agronomy, 1967. p.1-41.

COSTA, A. Doses emodos de aplicação de cal cário na implantação de sucessão soja trigo em sistema plantio direto. Botucatu, Universidade Estadual Paulista, 2000. 146p. (Tese de Doutorado)

EMPRESA BRASILEIRA DE PESQUISA AGROPECUÁRIA EMBRAPA. CentroNacional de Pesquisa de Solos. Manual de métodos de análise de solo. 2.ed. Rio de J aneiro, 1997. $212 p$.

ERNANI, P.R.; NASCIMENTO, J.A.L. \& OLIVEIRA, L.C. Increase of grain and green matter of corn by liming. R. Bras. Ci. Solo, 22:275-280, 1998.

ERNANI, P.R.; NASCIMENTO, J.A.L.; CAMPOS, M.L. \& CAMILLO, R.J. Influência da combinação de fósforo e calcário no rendimento de milho. R. Bras. Ci. Solo, 24:537544, 2000.

FREIRE, J.C. Resposta do milho a níveis de água e formas de aplicação de calcário em dois solos originalmente sob cerrado em casa de vegetação. R. Bras. Ci. Solo, 8:305308, 1984.

FURLANI, P.R. \& DUARTE, A.P. Tolerância ao alumínio em cultivares de milho. In: SEMINÁRIO NACIONAL DE MILHO SAFRINHA: valorização da produção e conservação de grãos no Mercosul, 6., Londrina, 2001. Anais. Londrina, FAPEAGRO, 2001. p.12.

GONZALES-ERICO, E.; KAMPRATH,E.J .; NADERMANN, G.C. \& SOARES, W.V. Effect of depth of lime incorporation on the growth of corn on an Oxisol of Central Brazil. Soil Sci. Soc. Am. J ., 43:1155-1158, 1979.

GOODROAD, L.L. \& J ELLUM, M.D. Effect of $\mathrm{N}$ fertilizer rate and soil pH on $\mathrm{N}$ efficiency in corn. Plant Soil, 106:85-89, 1988.

LOUÉ, A. Contribuição para o estudo da nutrição catiônica do milho, principalmentea do potássio. Fertilité, 20:1-57, 1963.

LUTZJ I., J .A.; GENTER, C.F. \& HAWKINS, G.W. Effect of soil $\mathrm{pH}$ on element concentration and uptake by maize: I. P, K, $\mathrm{Ca}, \mathrm{Mg}$ and Na. Agron. J., 64:581-583, 1972.

MALAVOLTA, E.; VITTI, G.C. \& OLIVEIRA, S.A. Avaliação do estado nutricional das plantas: princípios eaplicações. 2.ed. Piracicaba, POTAFOS, 1997. 319p.

MIYAZAWA, M.; PAVAN, M.A. \& CALEGARI, A. Efeito de material vegetal na acidez do solo. R. Bras. Ci. Solo, 17:411416, 1993.

MIYAZAWA, M.; PAVAN, M.A. \& SANTOS, J.C.F. Effects of addition of crop residues on the leaching of $\mathrm{Ca}$ and $\mathrm{Mg}$ in Oxysols. In:INTERNATIONAL SYMPOSIUM ON PLANTSOIL INTERACTIONS AT LOW pH, 4., Belo Horizonte, 1996. Abstracts. Belo Horizonte, Sociedade Brasileira de Ciência do Solo/ EMBRAPA-CPAC, 1996. p.8. 
MOSCHLER, W.W.; MARTENS, D.C.; RICH, C.I \& SHEAR, G.H. Comparative lime effects on continuous no-tillage and conventionally tilled corn. Agron. J., 65:781-783, 1973.

OLIVEIRA, E.L. \& PAVAN, M.A. Control of soil acidity in notillagesystem for soybean production. Soil Till. Res., 38:4757, 1996.

OLIVEIRA, E.L.; PARRA, M.S. \& COSTA, A. Resposta da cultura do milho, em um Latossolo Vermelho-Escuro álico, à calagem. R. Bras. Ci. Solo, 21:65-70, 1997.

PAVAN, M.A. Movimentação de calcário no solo através de técnicas de manejo da cobertura vegetal em pomares de macieira. R. Bras. Frutic., 16:86-91, 1994.

PAVAN, M.A.; BINGHAM, F.T. \& PRATT, P.F. Redistribution of exchangeable calcium, magnesium and al uminum following lime and gypsum applications to a Brazilian Oxisol. Soil Sci. Soc. Am. J., 48:33-38, 1984.

PAVAN, M.A.; BINGHAM, F.T. \& PRATT, P.F. Toxicity of aluminum to coffee in Ultisols and Oxisols amended with $\mathrm{CaCO}_{3}$ and $\mathrm{CaSO}_{4}$. Soil Sci. Soc. Am. J ., 46:1201-1207, 1982.

PAVAN, M.A.; BLOCH, M.F.; ZEMPULSKI, H.C.; MIYAZAWA, M. \& ZOCOLER , D.C. Manual de análise química do solo e controle de qualidade. Londrina, Instituto Agronômico do Paraná, 1992. 38p. (Circular, 76)

PEARSON, R.W.; ABRUNA, F. \& VICENTE-CHANDLER, J. Effect of lime and nitrogen applications on downward movement of calcium and magnesium in two humid tropical soils of Puerto Rico. Soil Sci., 93:77-82, 1962.

PÖTTKER, D. \& BEN, J.R. Calagem para uma rotação de culturas no sistema de plantio direto. R. Bras. Ci. Solo, 22:675-684, 1998.

QUAGGIO,J .A.; RAIJ , B. van; GALLO, P.B. \& MASCARENHAS, H.A.A. Respostas da soja à aplicação de cal cário e gesso e lixiviação de íons no perfil do solo. Pesq. Agropec. Bras., 28:375-383, 1993.

RAIJ, B. van; CAMARGO, A.P.; CANTARELLA, H. \& SILVA, N.M. Alumínio trocável e saturação em bases como critérios para recomendação decalagem. Bragantia, 42:149-156, 1983.
RAIJ , B. van; FURLANI, P.R.; QUAGGIO, J.A. \& PETTINELLI J r., A. Gesso na produção de cultivares de milho com tolerância diferencial a al umínio em três níveis de calagem. R. Bras. Ci. Solo, 22:101-108, 1998.

RHEINHEIMER, D.S.; SANTOS, E.J.S.; KAMINSKI, J. \& XAVIER, F.M. Aplicação superficial de cal cário no sistema plantio direto consolidado em solo arenoso. Ci. Rural, 30:263-268, 2000.

RITCHEY, K.D.; SI LVA, S.E. \& COSTA, V.F. Calcium deficiency in clayey B horizons of savannah Oxisols. Soil Sci., 133:378382, 1982.

RITCHEY, K.D.; SOUSA, D.M.G.; LOBATO, E. \& CORREA, O. Calcium leaching to increase rooting depth in a Brazilian Savannah Oxisol. Agron. J., 72:40-44, 1980.

ROSOLEM, C.A.;VALE, L.S.R.; GRASSI FILHO, H.\& MORAES, M.H. Sistema radicular e nutrição do milho em função da calagem e da compactação do solo. R. Bras. Ci. Solo, 18:491-497, 1994.

SALTON, J.C. \& MIELNICZUK, J. Relações entre sistemas de preparo, temperatura e umidade de um Podzólico Vermel hoEscuro de Eldorado do Sul (RS). R. Bras. Ci. Solo, 19:313319, 1995.

SCHENK, M.K. \& BARBER, S.A. Root characteristics of corn genotypes as related to P uptake. Agron. J., 71:921-924, 1979.

STOLF, R. Teoria e teste experimental de fórmulas de transformação dos dados de penetrômetro de impacto em resistência do solo. R. Bras. Ci. Solo, 15:229-235, 1991.

TENNANT, D. A test of a modified line intersect method of estimating root length. J. Ecol., 63:995-1001, 1975.

WEIR, C.C. Effect of lime and nitrogen application on citrus yields and on the downward movement of calcium and magnesium in a soil. Trop. Agric., 51:230-234, 1975.

ZIGLIO, C.M.; MIYAZAWA, M. \& PAVAN, M.A. Formas orgânicas e inorgânicas de mobilização do cálcio no solo. Braz. Arch. Biol. Technol., 42:257-262, 1999. 